Research Article

\title{
Highly Sensitive Amperometric $\alpha$-Ketoglutarate Biosensor Based on Reduced Graphene Oxide-Gold Nanocomposites
}

\author{
Gang Peng $\mathbb{D}^{1,2}$ Yadong Yu $\mathbb{D}^{1,3}$ Xiaojun Chen $\mathbb{D}^{1,},{ }^{4}$ and He Huang $\mathbb{D}^{1,3}$ \\ ${ }^{1}$ College of Biotechnology and Pharmaceutical Engineering, Nanjing Tech University, Nanjing 211800, China \\ ${ }^{2}$ College of Food Engineering, Anhui Science and Technology University, Fengyang 233100, China \\ ${ }^{3}$ College of Food Science and Pharmaceutical Engineering, Nanjing Normal University, Nanjing 210023, China \\ ${ }^{4}$ College of Chemistry and Molecular Engineering, Nanjing Tech University, Nanjing 211800, China
}

Correspondence should be addressed to Xiaojun Chen; chenxj@njtech.edu.cn and He Huang; huangh@njtech.edu.cn

Received 22 January 2020; Revised 31 May 2020; Accepted 15 June 2020; Published 1 August 2020

Academic Editor: Victoria F. Samanidou

Copyright ( $\odot 2020$ Gang Peng et al. This is an open access article distributed under the Creative Commons Attribution License, which permits unrestricted use, distribution, and reproduction in any medium, provided the original work is properly cited.

\begin{abstract}
Herein, a rapid and highly sensitive amperometric biosensor for the detection of $\alpha$-ketoglutarate $(\alpha-\mathrm{KG})$ was constructed via an electrochemical approach, in which the glutamate dehydrogenase (GLUD) was modified on the surface of reduced graphene oxide-gold nanoparticle composite $\left(\mathrm{rGO}-\mathrm{Au}_{\text {nano }}\right.$ composite). The $\mathrm{rGO}-\mathrm{Au}_{\text {nano }}$ composite was one-step electrodeposited onto glassy carbon electrode (GCE) surface and was characterized by scanning electron microscopy (SEM), energy dispersive X-ray spectroscopy (EDS), and electrochemical techniques. In addition, the $\mathrm{rGO}-\mathrm{Au}_{\text {nano }} / \mathrm{GCE}$ was also found to electrocatalyze the oxidation of $\beta$-nicotinamide adenine dinucleotide $(\mathrm{NADH})$ at the peak potential of $0.3 \mathrm{~V}$, which was negatively shifted compared with that at bare GCE or $\mathrm{Au}_{\text {nano }}$ /GCE, illustrating better catalytic performance of $\mathrm{rGO}-\mathrm{Au}_{\text {nano. }}$. After the modification of GLUD, the GLUD/rGO-Aun $\mathrm{un}_{\text {nano }} / \mathrm{GCE}$ led to effective amperometric detection of $\alpha$-KG through monitoring the NADH consumption and displayed a linear response in the range of 66.7 and $494.5 \mu \mathrm{M}$, with the detection limit of $9.2 \mu \mathrm{M}$. Moreover, the prepared GLUD/ $\mathrm{rGO}-\mathrm{Au}_{\text {nano }} / \mathrm{GCE}$ was further evaluated to be highly selective and used to test $\alpha$-KG in human serum samples. The recovery and the RSD values were calculated in the range of $97.9-102.4 \%$ and $3.8-4.5 \%$, respectively, showing a great prospect for its real application.
\end{abstract}

\section{Introduction}

$\alpha$-Ketoglutarate $(\alpha-\mathrm{KG})$ is an important metabolic marker of early diagnosis of cancer and microbial fermentation monitoring and also is a vital intermediate in the tricarboxylic acid cycle as well as a node to connect the carbonnitrogen metabolism in cells [1-4]. It has been emphasized to possess exciting angiogenesis suppressor activity [5-7]. Furthermore, micronutrient application of $\alpha$-KG has exhibited beneficial effects on several malignant tumors with only minor negative effects on normal cells $[4,5]$. Therefore, accurate and sensitive methods for the detection of $\alpha$-KG are urgently required. Till now, several methods have been developed for the quantification of $\alpha-\mathrm{KG}$, such as electrochemical [8], gas chromatography-mass spectrometry (GCMS) [4], and high-performance liquid chromatography
(HPLC) [5, 9]. Among them, electrochemical methods have become considerably meaningful due to the advantages of convenience, high speed, low cost, and easy-to-use. Currently, Wang and his coworkers have developed an electrochemical biosensor for rapid and sensitive detection of $\alpha$-KG based on ruthenium-rhodium modified carbon fiber enzyme microelectrode [8]. However, a large overpotential was found at the microelectrode and the detection of $\alpha$-KG was prone to suffer interference from other compounds. Therefore, it is important to prepare a capable modified electrode with lower overpotential for $\alpha$-KG detection and meanwhile maintain the bioactivity of the immobilized enzyme.

Graphene (Gr) has become extremely attractive in many fields since it has superiorities such as good biocompatibility [10], large surface-to-volume ratio, excellent conductivity 
[11], electron mobility, and flexibility [12]. In the electrochemical biosensing fields, its large surface-to-volume ratio is helpful for increasing the loading amount of the enzyme, and its excellent conductivity is favourable for transferring electrons between the electrode surface and electrolyte [13-19]. However, the practical applications of Gr are challenged by its irreversible agglomeration or even restack to form graphite due to the Van der Waals interactions in the drying state [20]. Recent research found that noble metal nanoparticles could be used to effectively prevent the massive agglomeration of Gr sheets. Si got a Pt nanoparticles $\left(\mathrm{Pt}_{\text {nano }}\right)-\mathrm{Gr}$ composite with the Gr partially exfoliated from its drying aqueous dispersions [21]. Tang et al. founded a rapid and efficient one-step approach to prepare $\mathrm{Gr}-\mathrm{Ag}_{\text {nano }}$ composite by simultaneous reduction of $\mathrm{Gr}$ oxide (GO) and $\mathrm{Ag}^{+}$with formaldehyde as the reducing agent [22]. Li et al. developed a sensor for the detection of paracetamol based on

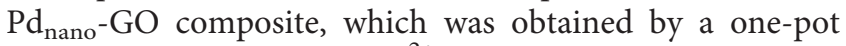
chemical reduction using $\mathrm{Pd}^{2+}$ as a precursor without large aggregation [23]. Also, noble metal nanoparticles-Gr composites have been found to have excellent catalytic performance in electrochemical biosensors [24-26]. Leng et al. demonstrated that the $\mathrm{Pd}_{\text {nano-GO composite could }}$ electrocatalyze the oxidation of rutin, with the detection limit of $0.001 \mu \mathrm{M}$ [27]. Govindhan et al. prepared $\mathrm{Au}_{\text {nano }}-\mathrm{Gr}$ composite which could catalyze NADH with the detection limit as low as $1.13 \mathrm{nM}$, since the composite provided a large electrochemical active surface area and a favourable environment for electron transfer from NADH to the electrode [28]. Therefore, in this work, we were ready to construct an $\alpha-\mathrm{KG}$ biosensor based on reduced GO- $\mathrm{Au}_{\text {nano }}\left(\mathrm{rGO}-\mathrm{Au}_{\text {nano }}\right)$ composite.

In this paper, the $\mathrm{rGO}-\mathrm{Au}_{\text {nano }}$ composite was one-step electrodeposited onto the glassy carbon electrode (GCE) surface, which exhibited a lower working potential for the electrochemical oxidation of $\mathrm{NADH}$, and served as the platform for the immobilization of glutamate dehydrogenase (GLUD). $\alpha$-KG was detected via monitoring the NADH consumption, and the mechanism was described as in the following equation [8]:

$$
\alpha-\mathrm{KG}+\mathrm{NH}_{4}^{+}+\mathrm{NADH} \stackrel{\text { GLUD }}{\longrightarrow} L-\text { Glutamate }+\mathrm{NAD}^{+}+\mathrm{H}_{2} \mathrm{O} .
$$

Catalyzed by GLUD, $\alpha$-KG was conversed to L-glutamate in the presence of $\mathrm{NH}_{4}{ }^{+}$and NADH. The more amount of $\alpha$-KG contained in solution, the more NADH was consumed. Then, if a certain amount of NADH was added in advance, the remaining amount of NADH would decrease along with the increase of $\alpha$-KG. Therefore, the concentration of $\alpha$-KG was inversely proportional to the catalytic current of $\mathrm{NADH}$, which provided the quantitative basis for $\alpha$-KG detection.

\section{Materials and Methods}

2.1. Materials and Reagents. GO was purchased from Suzhou Hengqiu Co., Ltd. (Suzhou, China). Chloroauric acid and ammonium chloride were obtained from Sinopharm Chemical Reagent Co., Ltd. (Shanghai, China). $\beta$-nicotinamide adenine dinucleotide reduced dipotassium salt $(\mathrm{NADH})$, L-Glutamic dehydrogenase from bovine liverType III (GLUD), and $\alpha$-ketoglutaric acid sodium salt $(\alpha-\mathrm{KG})$ were supplied by Sigma Chemical Co., Ltd. (St. Louis, MO, USA). The human serum samples were provided by Jiangsu Center for Clinical Laboratory (JSCCL). All other chemicals were of analytical grade and used without further purification. $0.05 \mathrm{M} \mathrm{pH} 9.0$ of carbonate buffer solution (CBS) and $0.1 \mathrm{M} \mathrm{pH} 7.2$ of phosphate buffered solution (PBS) were used as the electrolyte. Double-distilled water was used throughout the experiments.

\subsection{Characterization and Electrochemical Measurement.} Surface morphologies of $\mathrm{rGO}$ and $\mathrm{rGO}-\mathrm{Au}_{\text {nano }}$ films were investigated by scanning electron microscopy (SEM, JEOL, JSM-6510, Japan). The elemental composition analysis was performed by energy dispersive X-ray spectroscopy (EDS,
Vantage 4105, NORAN). All electrochemical measurements were carried out on a CHI 650E electrochemical workstation (Shanghai Chenhua Instrument Company, China), employing a typical three-electrode cell system. A modified or bare GCE was utilized as the working electrode $(\Phi=3 \mathrm{~mm})$, whereas a saturated calomel electrode (SCE) as a reference and a platinum foil electrode as a counter. All potentials were measured against SCE. All experiments were purged with high-purity nitrogen to remove oxygen and done at room temperature $\left(\sim 25^{\circ} \mathrm{C}\right)$.

2.3. Fabrication of $\alpha-K G$ Electrochemical Biosensor. The fabrication process of the electrochemical biosensor was illustrated in Scheme 1. Prior to electrodeposition, the GCE was polished using 0.3 and $0.05 \mu \mathrm{m}$ alumina powder until a mirror-shiny surface was obtained, and followed by ultrasonication in the ethanol and double-distilled water for $2 \mathrm{~min}$, respectively. The cleaned GCE was then modified by the electrochemical codeposition of the GO and $\mathrm{Au}_{\text {nano. }}$. According to the method reported by Liu et al. [29], GO was exfoliated in CBS by ultrasonication for $20 \mathrm{~min}$ to form a homogeneous few-layer GO dispersion. Cyclic voltammetric (CV) reduction was performed in the deposition solutions containing $1.0 \mathrm{mg} \cdot \mathrm{mL}^{-1}$ of GO and $200 \mu \mathrm{M}$ of chloroauric acid with magnetic stirring. The $\mathrm{CV}$ was carried out between -1.4 and $0.6 \mathrm{~V}$ at a rate of $20 \mathrm{mV} \cdot \mathrm{s}^{-1}$, and the deposition amount was optimized as six potential cycles. Then, $8 \mu \mathrm{L}$ of $110 \mathrm{kU} \cdot \mathrm{L}^{-1}$ GLUD PBS $(0.1 \mathrm{M}, \mathrm{pH} 7.2)$ was dropped onto $\mathrm{rGO}-\mathrm{Au}_{\text {nano }} / \mathrm{GCE}$ surface. After natural drying, it was dipped into a $2 \mathrm{wt} . \%$ of glutaraldehyde for $3 \mathrm{~s}$ to form a protective film and stored in PBS at $4^{\circ} \mathrm{C}$ before use. 


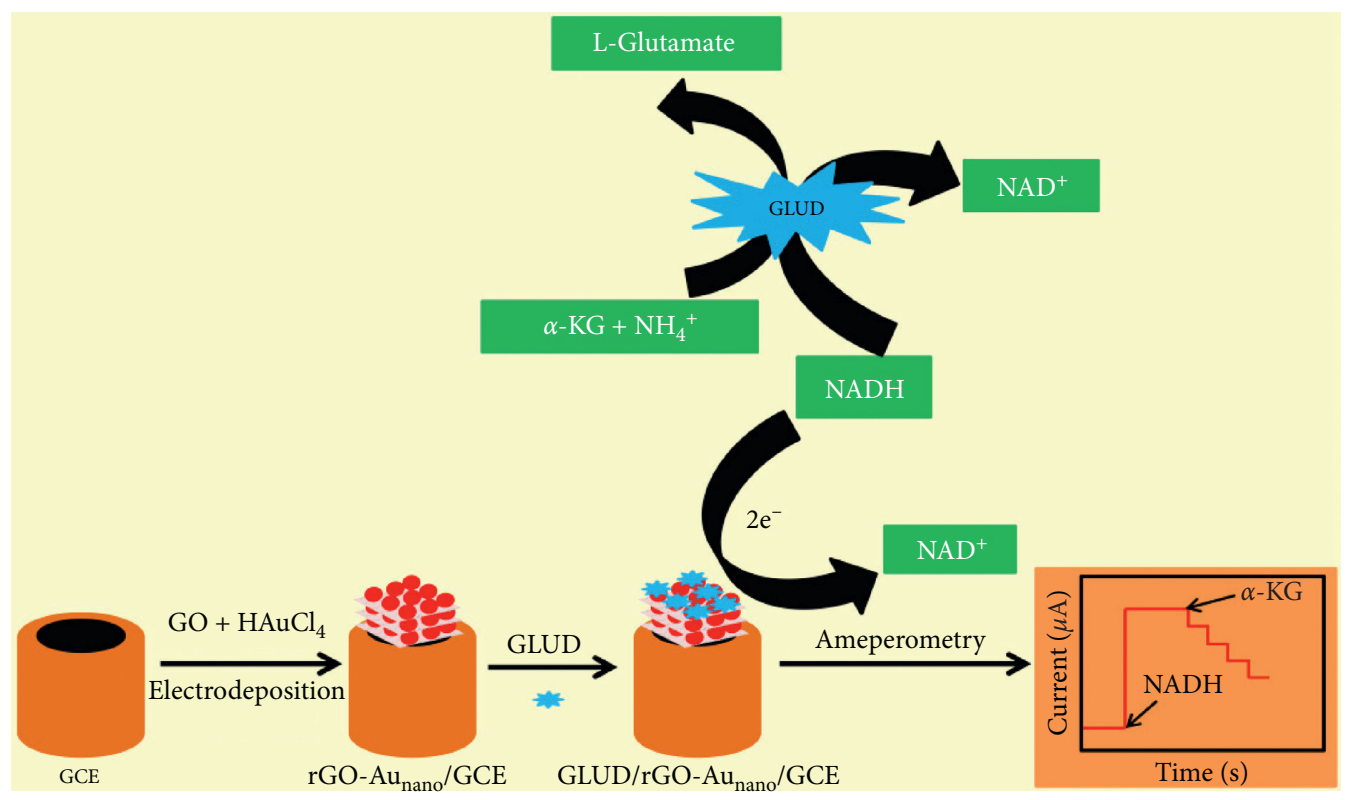

Scheme 1: Illustration of the preparation process and the sensing mechanism of the $\alpha$-KG biosensor.

\section{Results and Discussion}

3.1. Characterization of $r G O-A u_{\text {nano }}$ Composite. $\mathrm{CV}$ was recorded during the electrodeposition of GO on GCE (Figure 1(a)). There is one anodic peak (I) and two cathodic peaks (II and III), corresponding to the redox pair of some oxygen-containing groups [30] and the irreversible electrochemical reduction of GO [31], respectively. The ongoing increase of the peak current with successive potential sweeps indicated that the rGO from GO dispersion was successfully deposited onto GCE. Figure $1(\mathrm{~b})$ shows the CV of codeposition of GO and $\mathrm{HAuCl}_{4}$, with a completely different appearance from Figure 1(a). The reduction current was larger than that of GO electrolysis, indicating that the deposition of rGO and $\mathrm{Au}_{\text {nano }}$ onto the surface of GCE was achieved [29]. The number of electrodeposition cycles was also optimized since the thickness of the $\mathrm{rGO}-\mathrm{Au}_{\text {nano }}$ composite film would influence the conductivity and stability of the $\mathrm{rGO}-\mathrm{Au}_{\text {nano }} / \mathrm{GCE}$. This part would be interpreted in detail in the section of the optimization of the experimental parameters.

The morphologies of $\mathrm{rGO}$ and $\mathrm{rGO}-\mathrm{Au}_{\text {nano }}$ were characterized by SEM. Figure 1(c) shows the SEM image of rGO film, in which a typically wrinkled texture was displayed. In Figure $1(\mathrm{~d})$, you could find that $\mathrm{Au}_{\text {nano }}$ uniformly scattered over rGO to make the rGO- $\mathrm{Au}_{\text {nano }}$ composite. The $\mathrm{Au}_{\text {nano }}$ prevented the agglomeration of rGO; meanwhile, rGO enhanced the dispersion of $\mathrm{Au}_{\text {nano, }}$, both of which improve the conductivity and stability of $\mathrm{rGO}-\mathrm{Au}_{\text {nano }}$ composite film. Further, the EDS spectrum confirmed the elemental composition of $\mathrm{rGO}-\mathrm{Au}_{\text {nano, }}$, in which $\mathrm{Si}$ element comes from the Si substrate. The FT-IR spectra of GO and rGO are shown in Figure 2. The FT-IR spectrum of GO (a) exhibits the characteristic absorptions from oxygen-containing functional groups. In detail, the absorption band at 3437 and
$1397 \mathrm{~cm}^{-1}$ can be assigned to the stretching vibration and deformation vibration of $\mathrm{O}-\mathrm{H}$, respectively. The band at $1052 \mathrm{~cm}^{-1}$ belongs to the $\mathrm{C}-\mathrm{O}$ (alkoxy), while the band at $1633 \mathrm{~cm}^{-1}$ derives from the vibration of the adsorbed water molecules and/or the contribution of the skeletal vibration of unoxidized graphitic domains. After the reduction, the peaks at $1070 \mathrm{~cm}^{-1}$ assigned to epoxy groups are decreased significantly, clearly indicating the removal of oxygen-containing groups of GO (curve b in Figure 2) and suggesting the successful reduction of GO [32].

3.2. Electrochemical Performance of $r G O-A u_{\text {nano }}$ Composite. Figure 3(a) presents the CVs of four different modified GCEs in $0.1 \mathrm{M} \mathrm{KCl}$ containing $5 \mathrm{mM}$ of $\left[\mathrm{Fe}(\mathrm{CN})_{6}\right]^{3-/ 4-}$ at a scan rate of $50 \mathrm{mV} \cdot \mathrm{s}^{-1}$. The current response of $\mathrm{rGO} / \mathrm{GCE}$ (curve $B$ towards $\left.\left[\mathrm{Fe}(\mathrm{CN})_{6}\right]^{3-/ 4-}\right)$ was larger than that of bare GCE (curve A), owing to that $\mathrm{rGO}$ enhanced the electron transfer ability. The similarly enhanced peak current at $\mathrm{Au}_{\text {nano }} / \mathrm{GCE}$ (curve C) attributed to the good conductivity of $\mathrm{Au}_{\text {nano. }}$. After the $\mathrm{rGO}-\mathrm{Au}_{\text {nano }}$ composite modified onto the GCE surface (curve $\mathrm{D}$ ), the peak current rose further owing to the synergy from $\mathrm{rGO}$ and $\mathrm{Au}_{\text {nano. The electrochemical prop- }}$ erties of these modified electrodes were also characterized by EIS. Figure 3(b) shows nearly straight lines at $\mathrm{rGO} / \mathrm{GCE}$ (curve $\mathrm{B}$ ), $\mathrm{Au}_{\text {nano }} / \mathrm{GCE}$ (curve C), and $\mathrm{rGO}-\mathrm{Au}_{\text {nano }} / \mathrm{GCE}$ (curve D), revealing rapid electron transfer between the electrode surface and the electrolyte. Only a small semicircle was observed at bare GCE (curve A), which meant about $100 \Omega$ of electron transfer resistance in this system.

$\mathrm{CV}$ technique was also performed to evaluate the electrocatalytic oxidation effect of NADH on different electrodes in $0.1 \mathrm{M}$ PBS (pH 7.2) containing $0.5 \mathrm{mM}$ of NADH at a scan rate of $50 \mathrm{mV} \cdot \mathrm{s}^{-1}$. As shown in Figure 3(c), a very small anodic peak was obtained at $0.7 \mathrm{~V}$ at the bare GCE (curve A), 


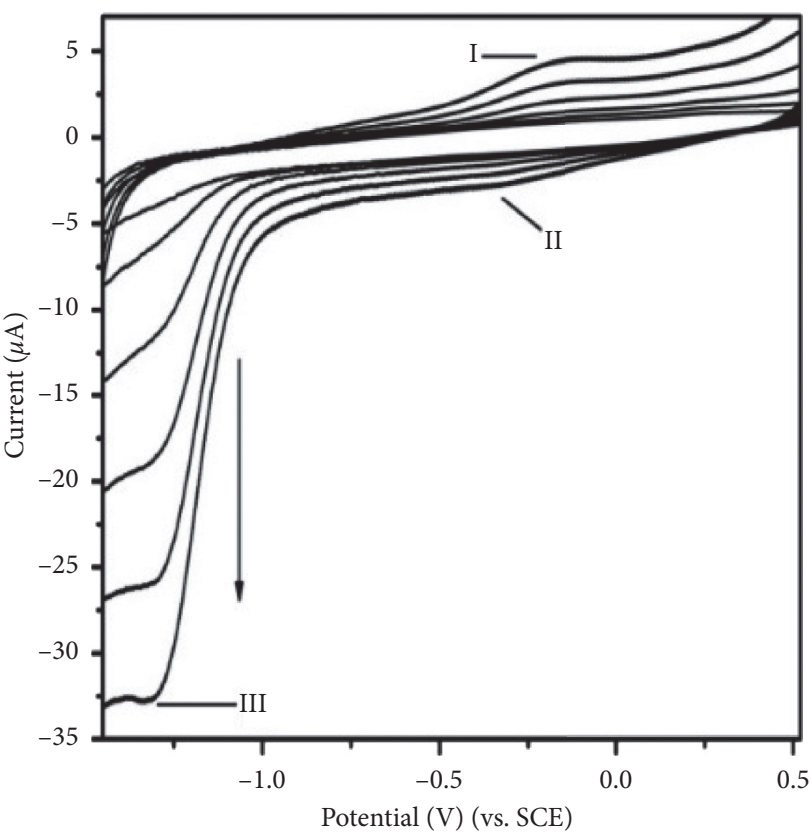

(a)

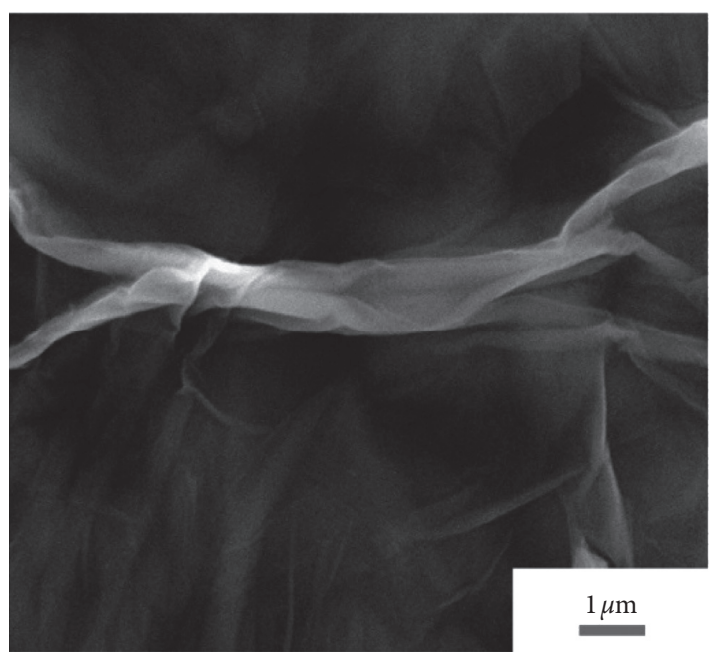

(c)

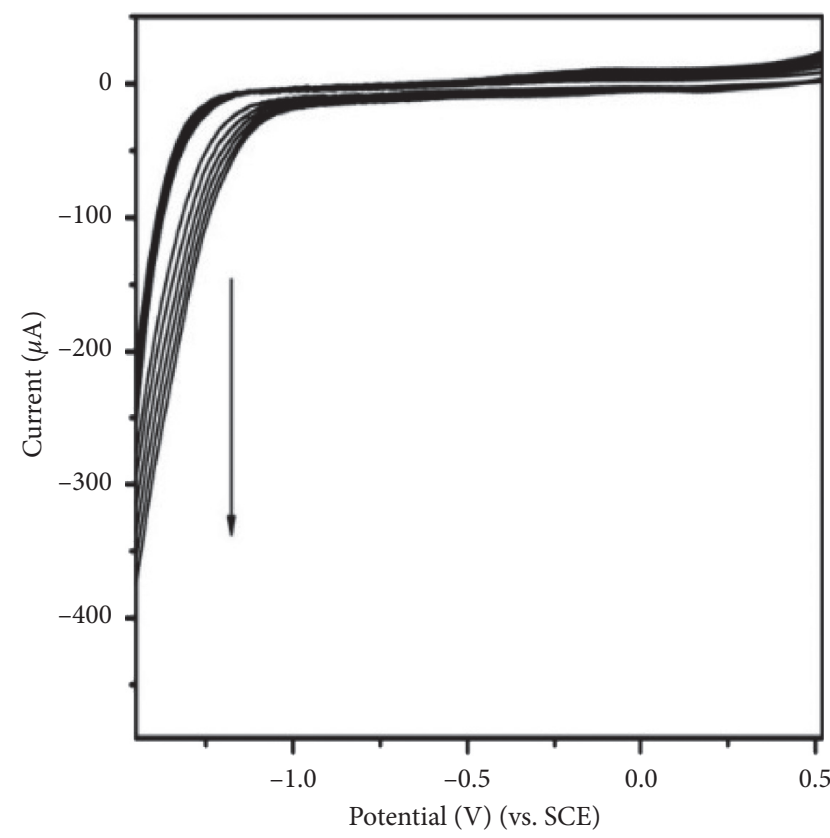

(b)

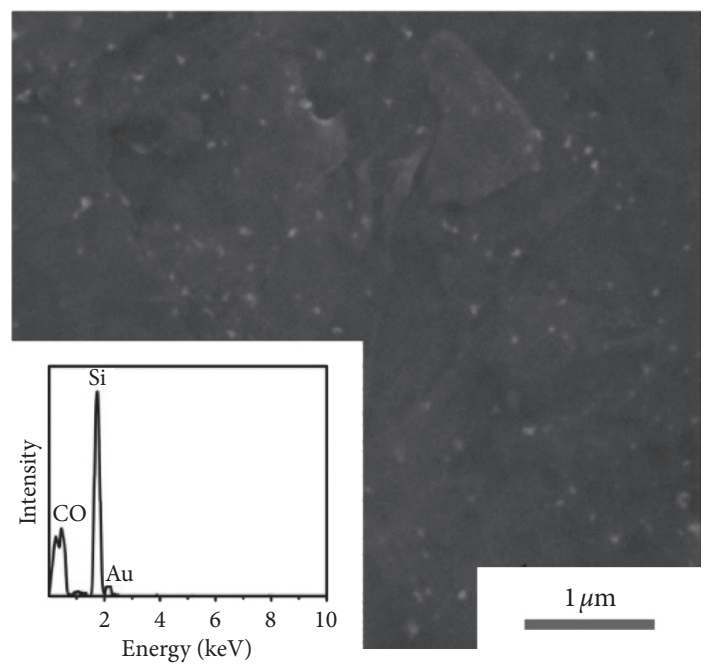

(d)

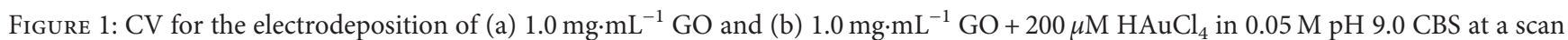
rate of $20 \mathrm{mV} \cdot \mathrm{s}^{-1}$. Typical SEM images obtained from (c) rGO and (d) rGO-Aunano film on Si substrate, respectively. Inset: EDS pattern of the $\mathrm{rGO}-\mathrm{Au}_{\text {nano }}$.

which meant that the direct oxidation of NADH at the bare electrode was difficult. After the modification of $\mathrm{Au}_{\text {nano, }}$, the anodic peak increased and the working potential negatively shifted to $0.62 \mathrm{~V}$, which might be owing to the good oxidation catalytic ability of $\mathrm{Au}_{\text {nano }}$ (curve B) [32]. For the rGO/ GCE as curve C, a small oxidation peak at $0.24 \mathrm{~V}$ was found, showing the excellent catalytic capacity of rGO to NADH and the activation energy of NADH oxidation was declined on the surface of rGO. The reason might be that the presence of abundant defects and edge plane graphite structures in rGO was thought to facilitate the heterogeneous charge transfer at the electrode interface $[25,33,34]$. Thus, the electrons released by $\mathrm{NADH}$ could be transferred swiftly with the aid of rGO. After the combination of $\mathrm{Au}_{\text {nano }}$ and rGO, the oxidation peak current of NADH was similar to that of $\mathrm{Au}_{\text {nano }} / \mathrm{GCE}$, and the peak potential appeared at $0.32 \mathrm{~V}$. The synergic effect of the $\mathrm{rGO}$ and $\mathrm{Au}_{\text {nano }}$ exhibited the capability as a powerful catalyst to the oxidation of $\mathrm{NADH}$ [35]. In addition, we also found that no obvious peaks were observed on all these four modified electrodes in PBS without NADH (Figure S1), indicating NADH could be catalytically oxidized with the aid of $\mathrm{Au}_{\text {nano }}$ and $\mathrm{rGO}$.

The effect of the scan rate on the oxidation current of $\mathrm{NADH}$ was also investigated. The CVs of the $\mathrm{rGO}-\mathrm{Au}_{\text {nano }} / \mathrm{GCE}$ at different scan rates were recorded as Figure 3(d). A good linear relationship of the anodic peak current with the square 


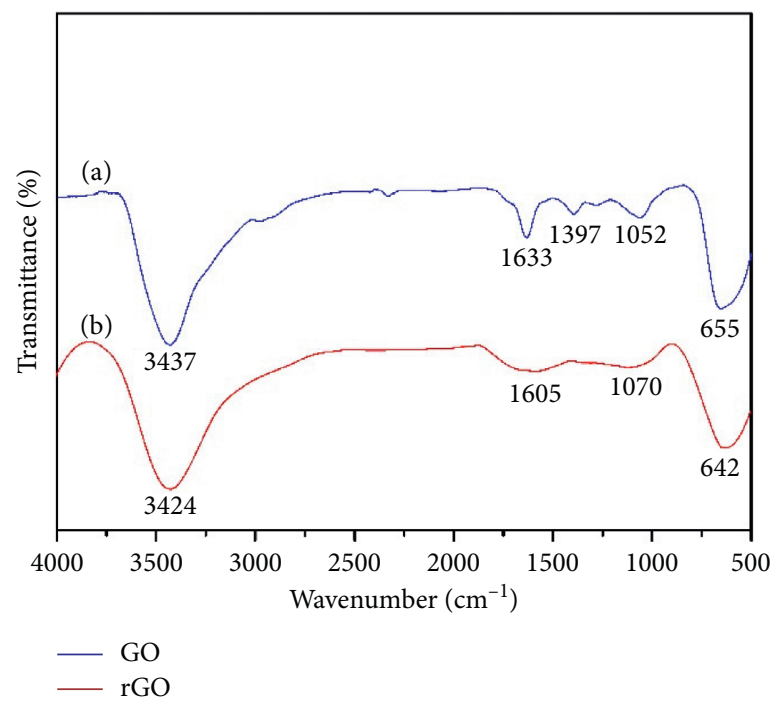

Figure 2: FT-IR spectra of GO (a) and rGO (b).

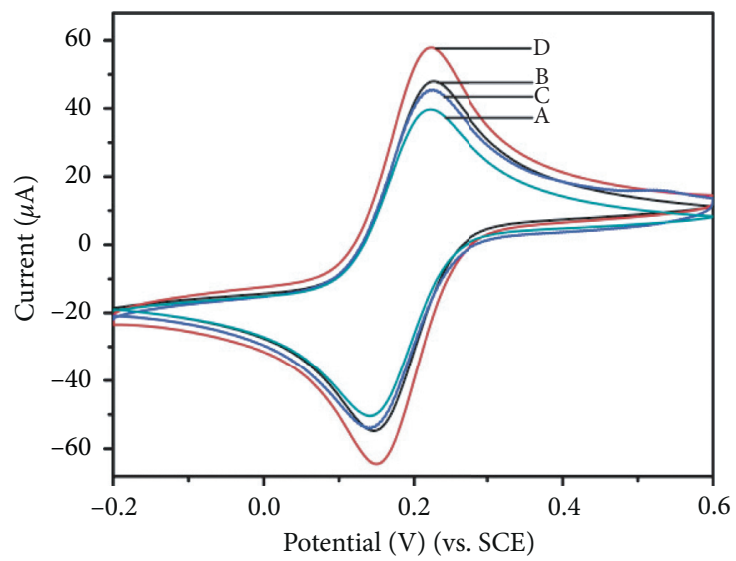

(a)

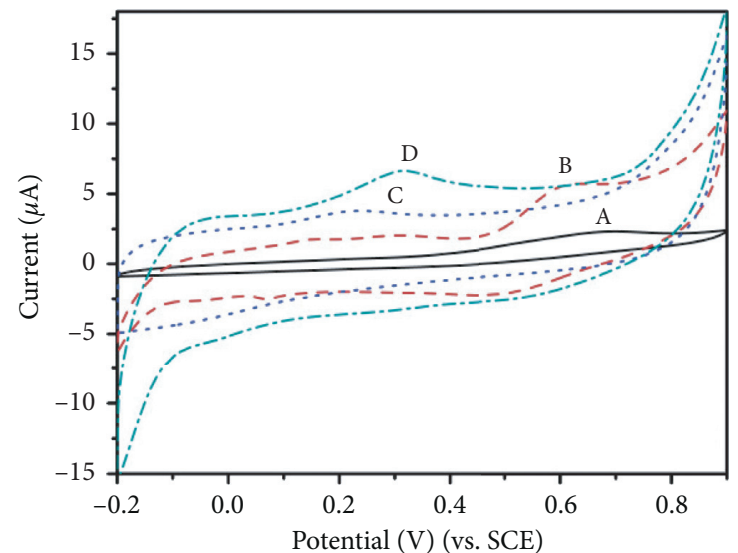

(A) bare GCE

(C) $\mathrm{rGO} / \mathrm{GCE}$

- - (B) $\mathrm{Au}_{\text {nano }} / \mathrm{GCE}$

(c)

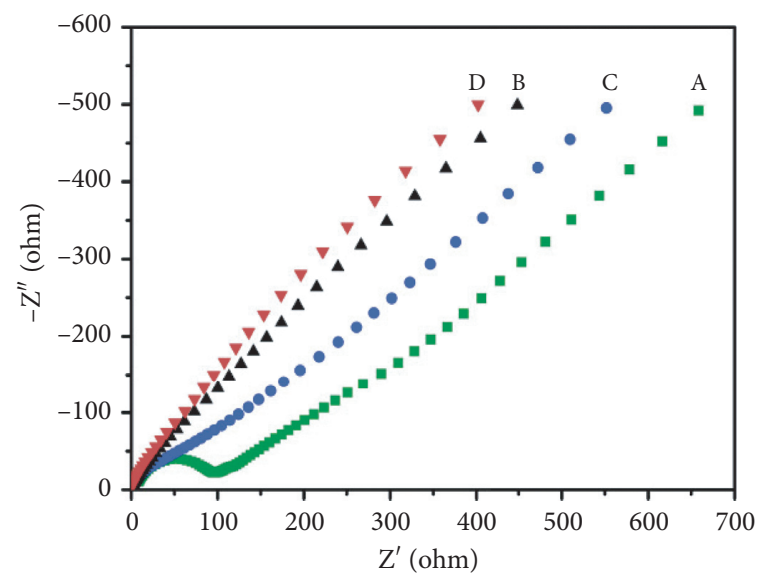

(b)

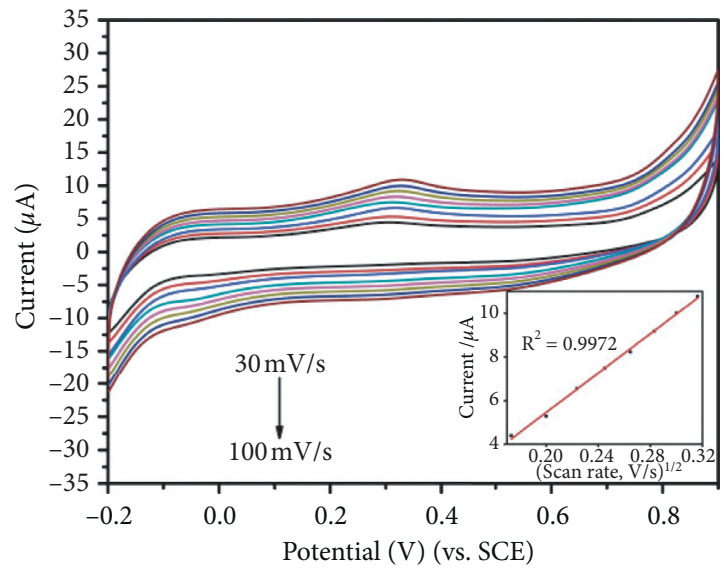

(d)

Figure 3: (a) CVs and (b) EIS of the different electrodes: bare GCE (A), rGO/GCE (B), $\mathrm{Au}_{\text {nano }} / \mathrm{GCE}(\mathrm{C})$, and $\mathrm{rGO}-\mathrm{Au}_{\text {nano }} / \mathrm{GCE}$ (D) in 0.1 M $\mathrm{KCl}$ containing $5.0 \mathrm{mM}\left[\mathrm{Fe}(\mathrm{CN})_{6}\right]^{3-/ 4-}$ at a scan rate of $50 \mathrm{mV} \cdot \mathrm{s}^{-1}$. (c) CVs of the different working electrode in the presence of $0.5 \mathrm{mM}$ $\mathrm{NADH}$ at a scan rate of $50 \mathrm{mV} \cdot \mathrm{s}^{-1}$. (d) CVs of rGO-Au $\mathrm{unno}_{\text {no }} / \mathrm{GCE}$ in $0.5 \mathrm{mM} \mathrm{NADH}$ at various scan rates (from inner to outer: $30,40,50,60$, $70,80,90$ and $\left.100 \mathrm{mV} \cdot \mathrm{s}^{-1}\right)$. Inset: the plot of anodic peak current against the square root of the scan rate. 
root of the scan rate in the range of 30 and $100 \mathrm{mV} \cdot \mathrm{s}^{-1}$ was presented as the inset of Figure 3(d). The result revealed the oxidation of $\mathrm{NADH}$ on the $\mathrm{rGO}-\mathrm{Au}_{\text {nano }} / \mathrm{GCE}$ was a diffusioncontrolling process, owing to the fast electron transfer rate between $\mathrm{rGO}-\mathrm{Au}_{\text {nano }}$ and the electrolyte.

3.3. Optimization of the Experimental Parameters. To improve the performance of the NADH sensor, the effect of determination conditions such as the electrodeposition cycles, the applied potential, and the solution $\mathrm{pH}$ have been investigated in detail.

The number of the electrodeposition cycles was optimized by measuring the catalytic current to $0.5 \mathrm{mM} \mathrm{NADH}$ using $\mathrm{rGO}-\mathrm{Au}_{\text {nano }} / \mathrm{GCE}$ with a different $\mathrm{rGO}-\mathrm{Au}_{\text {nano }}$ film. The more electrodeposition cycles exerted, the thicker the rGO- $\mathrm{Au}_{\text {nano }}$ composite film would be obtained. As shown in Figure 4(a), the oxidation peak current increased sharply as increasing the electrodeposition cycle number from 2 to 6 , due to the enhanced conductivity and catalytic activity along with increasing $\mathrm{rGO}-\mathrm{Au}_{\text {nano }}$ deposition. However, the peak current decreased when the number of electrodeposition cycles was more than 6 , owing to the fact that the thicker rGO-Au $u_{\text {nano }}$ film was inclined to drop off. Thus, 6 cycles of electrodeposition of $\mathrm{rGO}-\mathrm{Au}_{\text {nano }}$ deposition were selected in this work.

In order to achieve the best electrocatalytic effect while reducing the overpotential, the applied potential should be optimized. The effect of the applied potential was shown in Figure 4(b). As the applied potential increased from 0.1 to $0.3 \mathrm{~V}$, the peak current increased gradually. Further, increasing the applied potential from 0.3 to $0.7 \mathrm{~V}$ led to a relatively constant current value. Therefore, $0.3 \mathrm{~V}$ was selected as the optimal applied potential.

The effect of the solution $\mathrm{pH}$ on the oxidation of $\mathrm{NADH}$ at $\mathrm{rGO}-\mathrm{Au}_{\text {nano }} / \mathrm{GCE}$ was also studied by monitoring the peak current of $\mathrm{NADH}$ in $0.1 \mathrm{M}$ PBS with different $\mathrm{pH}$ values from 6.0 to 8.0. Figure 4(c) shows that the oxidation peak current of $\mathrm{NADH}$ increased along with the solution $\mathrm{pH}$ value from 6.0 to 7.2 , and then decreased. Therefore, $\mathrm{pH} 7.2$ was selected as the optimum for further studies.

3.4. Detection of $\alpha-K G$ Using $G L U D / r G O-A u_{\text {nano }} / G C E$. Based on the catalytic mechanism described in the introduction part, the concentration of $\alpha$-KG could be determined by the depleted amount of $\mathrm{NADH}$ at a GLUD/rGO-Aunano/GCE. That is to say, the content of $\alpha$-KG was inversely proportional to the catalytic current of NADH. To obtain the optimal performance of the biosensor, the concentration of the immobilized GLUD needed to be investigated further. As seen from Figure 5(a), the current response of NADH decreased quickly along with the GLUD concentration increased from 27.5 to $110 \mathrm{kU} \cdot \mathrm{L}^{-1}$, showing a fast transform from $\alpha$-KG to L-glutamate. Then, the current tended to become steady with a further increase in GLUD concentration, owing to the saturation of GLUD loading capacity. From an economic perspective, $110 \mathrm{kU} \cdot \mathrm{L}^{-1}$ of GLUD was selected in our experiments.
Figure 5(b) shows a typical amperometric current-time curve recorded at GLUD/rGO-Au nano $_{\text {GCE }}$ for the successive additions of $66.7 \mu \mathrm{M} \alpha-\mathrm{KG}$ in a stirred pH 7.2 PBS containing $1 \mathrm{mM} \mathrm{NADH}$ and $1 \mathrm{mM} \mathrm{NH}_{4} \mathrm{Cl}$. The response was very fast and the steady-state current response was attained in less than $5 \mathrm{~s}$. The linear response range at GLUD/ rGO-Au nano $/ \mathrm{GCE}$ was from 66.7 to $494.5 \mu \mathrm{M}$, with the sensitivity of $454 \mu \mathrm{A} \mathrm{M}^{-1}$ and a correlation coefficient of 0.9992. The calculated limit of detection was found to be $9.2 \mu \mathrm{M}(\mathrm{S} / \mathrm{N}=3)$. After the GLUD immobilization, the biosensor sensitivity was decreased due to the enzyme layer act as a barrier that hindered NADH transport. To our knowledge, there are few reports on electrochemical biosensors for the measurement of $\alpha$-KG, and nearly a few references could be compared. As listed in Table 1, our sensing system exhibited a comparable linear range with a bienzymatic flow injection system [37] and a similar detection limit with the other electrochemical biosensors, suggesting the proposed sensor had a good performance in $\alpha$-KG detection.

3.5. Reproducibility, Stability, and Selectivity of the Biosensor.

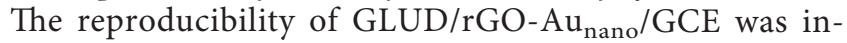
vestigated in $0.1 \mathrm{M}$ PBS containing $1 \mathrm{mM} \mathrm{NADH}$ and $1 \mathrm{mM} \mathrm{NH}_{4} \mathrm{Cl}$ via recoding the current response during the successive addition of $66.7 \mu \mathrm{M}$ of $\alpha$-KG. Six sensors were prepared in different batches, and 10 successive measurements were implemented for each electrode, and the RSD of the current response was 4.8 and $4.2 \%$, respectively. The stability of GLUD/rGO-Aunano/GCE was also evaluated. The current response for $312.5 \mu \mathrm{M} \alpha$-KG was measured, and there was nearly no apparent loss during $\sim 1000$ s' operation, as shown in Figure 6(a). Such good stability of GLUD/rGO-Aun $\mathrm{nano}_{\text {no }} / \mathrm{GCE}$ was attributed to the protection of the glutaraldehyde membrane and the biocompatibility of rGO-Aun $\mathrm{uno}_{\text {nano }}$ for GLUD immobilization.

Selectivity is important for the practical application of biosensors. An assessment of the interference on the amperometric response to $\mathrm{NADH}$ was examined at the $\mathrm{GLUD} / \mathrm{rGO}-\mathrm{Au}_{\text {nano }} / \mathrm{GCE}$ in the presence of other oxidizable substances, such as dopamine (DA), ascorbic acid (AA), and uric acid (UA). Figure 6(b) shows the amperometric responses at GLUD/rGO-Au nano $_{\text {/GCE }}$ after the addition of various interferents. In the presence of $0.25 \mathrm{mM}$ $\mathrm{NADH}, 0.1 \mathrm{mM}$ DA or UA could not induce apparent interference, while $0.1 \mathrm{mM}$ AA generated an obvious interference, since AA could be oxidized at lower potential compared with DA and UA $[38,39]$. Thus, AA should be removed when the biosensor was used for practical application. One possible method for removing AA was the immobilization of ascorbate oxidase onto the electrode surface [40].

3.6. Real Sample Analysis in Human Serum. The designed $\mathrm{GLUD} / \mathrm{rGO}-\mathrm{Au}_{\text {nano }} / \mathrm{GCE}$ was further evaluated in real human serum using the standard addition method. The human serum was diluted 10 times with $0.1 \mathrm{M} \mathrm{pH}$ 7.2 PBS. 


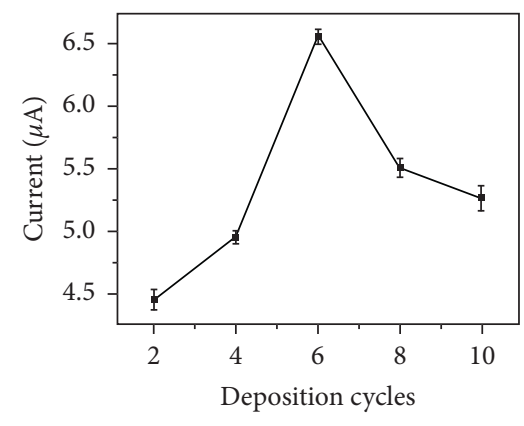

(a)

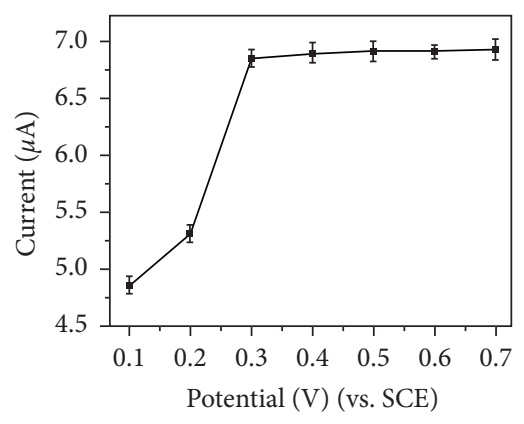

(b)

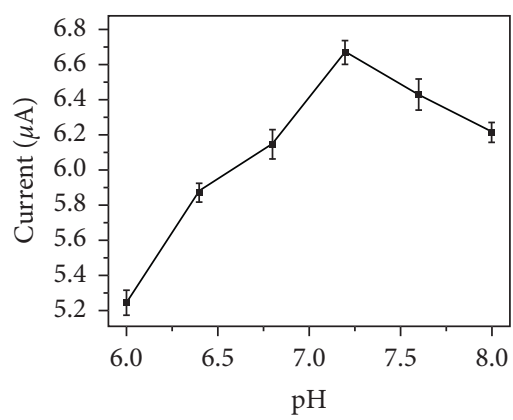

(c)

FIGURE 4: The effect of the catalytic current of $0.5 \mathrm{mM}$ NADH against the (a) number of the electrodeposition circles of rGO-Au $\mathrm{u}_{\text {nano }}$ film, (b) applied potential, and (c) solution $\mathrm{pH}$.

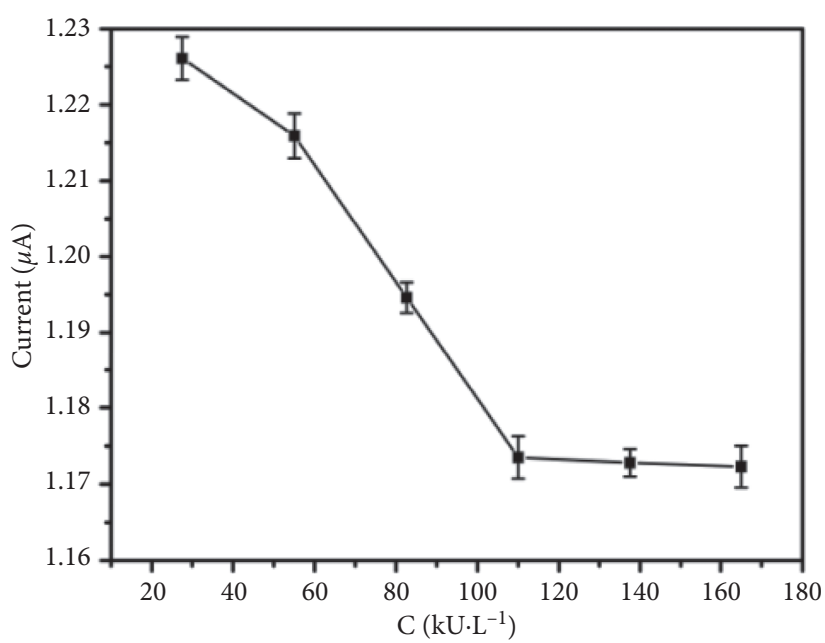

(a)

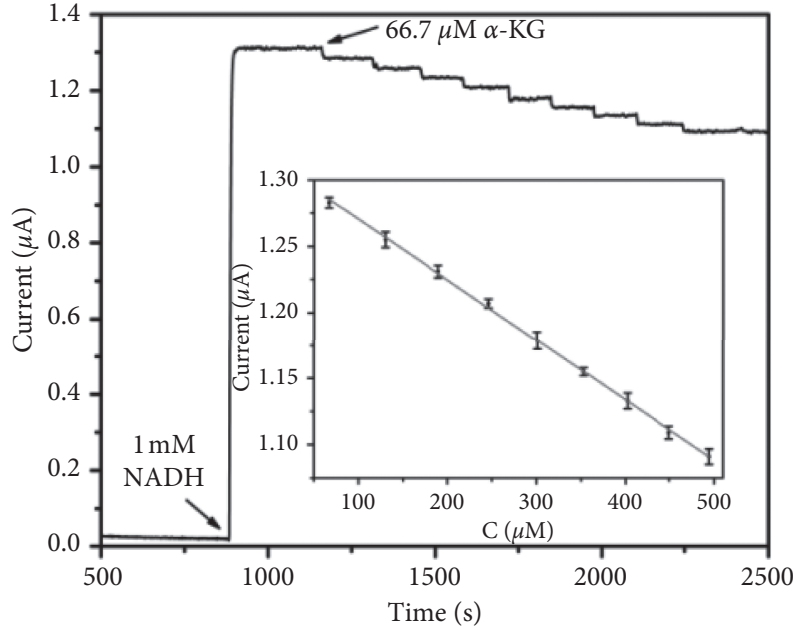

(b)

FIgURE 5: (a) The effect of GLUD concentration on the current response of NADH at GLUD/rGO-Aunano/GCE in $0.1 \mathrm{M}$ pH $7.2 \mathrm{PBS}$ containing $312.5 \mu \mathrm{M}$ of $\alpha-\mathrm{KG}, 1 \mathrm{mM}$ of NADH and $1 \mathrm{mM} \mathrm{NH}_{4} \mathrm{Cl}$. (b) Amperometric current-time curve recorded at GLUD/rGO-Aun $/ \mathrm{GCE}$ for the successive additions of $66.7 \mu \mathrm{M} \alpha-\mathrm{KG}$ in a stirred $\mathrm{pH}$ 7.2 PBS containing $1 \mathrm{mM} \mathrm{NADH}$ and $1 \mathrm{mM} \mathrm{NH}_{4} \mathrm{Cl}$. The applied potential was $0.3 \mathrm{~V}$ and the stirring rate was set as $200 \mathrm{rpm}$.

TABLE 1: Comparison of $\alpha$-KG detection performance with sensors.

\begin{tabular}{lccc}
\hline$\alpha$-KG sensor & Linear range $(\mu \mathrm{M})$ & Detection limit $(\mu \mathrm{M})$ & Ref. \\
\hline GLUD-Ru/Rh & $100-600$ & 20 & {$[8]$} \\
GLUD-rMNs- $\mathrm{Au}_{\text {nano }}$ & $11.12-52.94$ & 6.25 & {$[36]$} \\
GDH-GlOx & $0-500$ & 7 & {$[37]$} \\
GLUD/rGO-Aunano & $66.7-494.5$ & 9.2 & This work \\
\hline
\end{tabular}

Then, the solution was transferred into the electrochemical cell for analysis. The amperometric current-time measurement was employed for the recovery test to determine $\alpha$-KG in the human serum samples. As listed in Table 2, the recoveries of $\alpha$-KG between 97.9 and $102.4 \%$ with RSD values in the range of 3.8 to $4.5 \%$ were obtained, indicating the strong potential application prospect in clinical diagnosis. 


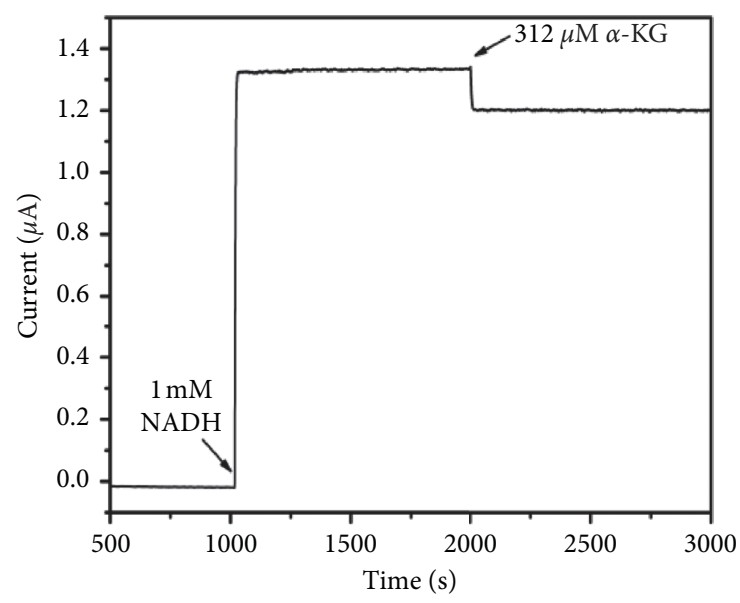

(a)

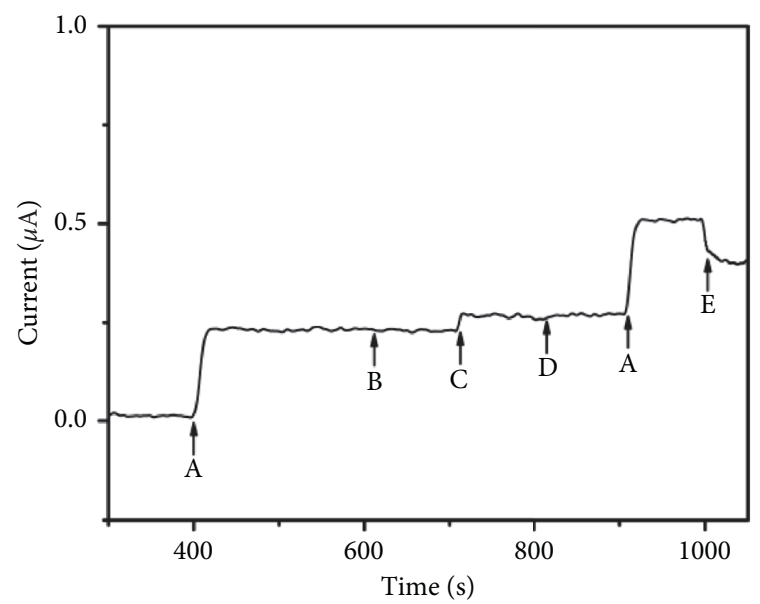

(b)

Figure 6: (a) Amperometric current-time curve showing the stability of the $\alpha$-KG response at the GLUD/rGO-Aunano $/ \mathrm{GCE}$. The first arrow indicates the addition of $1 \mathrm{mM} \mathrm{NADH}$ and the second arrow indicates the addition of $312.5 \mu \mathrm{M} \alpha$-KG. (b) Amperometric current-time curve

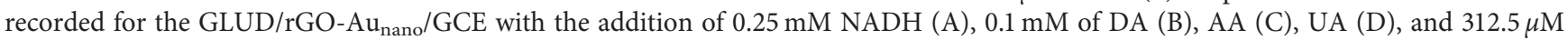
$\alpha$-KG (E). The applied potential was $0.3 \mathrm{~V}$. Stirring rate: $200 \mathrm{rpm}$.

TABLE 2: Recovery test of $\alpha$-KG in human serum samples $(n=3)$.

\begin{tabular}{lcccc}
\hline Sample & Added $(\mu \mathrm{M})$ & Found $(\mu \mathrm{M})^{\mathrm{a}}$ & Recovery (\%) & RSD (\%) \\
\hline 1 & 100 & 102.4 & 102.4 & 4.5 \\
2 & 200 & 197.6 & 98.8 & 3.8 \\
3 & 300 & 293.7 & 97.9 & 4.3 \\
\hline
\end{tabular}

${ }^{a}$ Average of three measurements.

\section{Conclusion}

In this work, an $\alpha$-KG biosensor based on the $\mathrm{rGO}-\mathrm{Au}_{\text {nano }}$

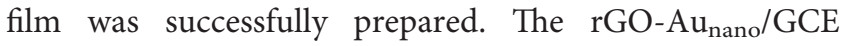
platform resulted in the improvement of electrocatalytic activity towards the oxidation of NADH with lower working potential, higher sensitivity, stability, and reproducibility. After the modification of GLUD, the electrode exhibited a sensitive response to $\alpha$-KG in PBS via the consumption of $\mathrm{NADH}$, implying good stability of GLUD on biocompatible rGO-Aunano platform and rapid electron transfer ability between electrode and $\alpha$-KG. Moreover, the biosensor was applied to determine $\alpha$-KG in human serum with satisfactory recoveries, illustrating its good selectivity and antiinterference. To summarize, the $\alpha$-KG sensing strategy reported in this work could be expected for real applications in the future.

\section{Data Availability}

The data that support the findings of this study are available from the corresponding author upon reasonable request.

\section{Conflicts of Interest}

The authors declare that they have no conflicts of interest.

\section{Acknowledgments}

This study was financially supported by the National Natural Science Foundation of China (21575064), the Six Talent Peaks Project in Jiangsu Province (2016-SWYY-022), the Qinglan Project of Jiangsu Education Department (2016), and the Program for Innovative Research Team in Universities of Jiangsu Province (2015).

\section{Supplementary Materials}

Figure S1: CVs of different working electrodes in $0.1 \mathrm{M} \mathrm{pH}$ 7.2 PBS without NADH at a scan rate of $50 \mathrm{mV} \cdot \mathrm{s}^{-1}$. (Supplementary Materials)

\section{References}

[1] S. Zhao, Y. Lin, W. Xu et al., "Glioma-derived mutations in IDH1 dominantly inhibit IDH1 catalytic activity and induce HIF-1," Science, vol. 324, no. 5924, pp. 261-265, 2009.

[2] H. A. Krebs and P. P. Cohen, "Metabolism of $\alpha$-ketoglutaric acid in animal tissues," Biochemical Journal, vol. 33, no. 11, pp. 1895-1899, 1939.

[3] J. E. Baldwin and H. Krebs, "The evolution of metabolic cycles," Nature, vol. 291, no. 5814, pp. 381-382, 1981.

[4] B. M. Wagner, F. Donnarumma, R. Wintersteiger, W. Windischhofer, and H. J. Leis, "Simultaneous quantitative determination of $\alpha$-ketoglutaric acid and 5-hydroxymethylfurfural in human plasma by gas chromatographymass spectrometry," Analytical and Bioanalytical Chemistry, vol. 396, no. 7, pp. 2629-2637, 2010.

[5] K. Michail, H. Juan, A. Maier, V. Matzi, J. Greilberger, and R. Wintersteiger, "Development and validation of a liquid chromatographic method for the determination of hydroxymethylfurfural and alpha-ketoglutaric acid in human plasma," Analytica Chimica Acta, vol. 581, no. 2, pp. 287-297, 2007.

[6] W. Schreibmayer, R. J. Schaur, H. M. Tillian, E. Schauenstein, and K. Hagmüller, "Tumor host relations," Journal of Cancer 
Research and Clinical Oncology, vol. 97, no. 2, pp. 137-144, 1980.

[7] R. J. Schaur, W. Schreibmayer, H.-J. Semmelrock, H. M. Tillian, and E. Schauenstein, "Tumor host relations," Journal of Cancer Research and Clinical Oncology, vol. 93, no. 3, pp. 293-300, 1979.

[8] S. Poorahong, P. Santhosh, G. V. Ramírez et al., "Development of amperometric $\alpha$-ketoglutarate biosensor based on ruthenium-rhodium modified carbon fiber enzyme microelectrode," Biosensors and Bioelectronics, vol. 26, no. 8, pp. 3670-3673, 2011.

[9] H. Terada, T. Hayashi, S. Kawai, and T. Ohno, "High-performance liquid chromatographic determination of pyruvic acid and $\alpha$-ketoglutaric acid in serum," Journal of Chromatography A, vol. 130, pp. 281-286, 1977.

[10] X. Y. Zhang, J. L. Yin, C. Peng et al., "Distribution and biocompatibility studies of graphene oxide in mice after intravenous administration," Carbon, vol. 49, no. 3, pp. 986995, 2011.

[11] A. A. Balandin, S. Ghosh, W. Bao et al., "Superior thermal conductivity of single-layer graphene," Nano Letters, vol. 8, no. 3, pp. 902-907, 2008.

[12] U. Stöberl, U. Wurstbauer, W. Wegscheider, D. Weiss, and J. Eroms, "Morphology and flexibility of graphene and fewlayer graphene on various substrates," Applied Physics Letters, vol. 93, no. 5, Article ID 051906, 2008.

[13] Y. Liu, D. Yu, C. Zeng, Z. Miao, and L. Dai, "Biocompatible graphene oxide-based glucose biosensors," Langmuir, vol. 26, no. 9, pp. 6158-6160, 2010.

[14] K. Zhou, Y. Zhu, X. Yang, J. Luo, C. Li, and S. Luan, "A novel hydrogen peroxide biosensor based on Au-graphene-HRPchitosan biocomposites," Electrochimica Acta, vol. 55, no. 9, pp. 3055-3060, 2010.

[15] J. Yang, S. Deng, J. Lei, H. Ju, and S. Gunasekaran, "Electrochemical synthesis of reduced graphene sheet-AuPd alloy nanoparticle composites for enzymatic biosensing," Biosensors and Bioelectronics, vol. 29, no. 1, pp. 159-166, 2011.

[16] Q. He, J. Liu, X. Liu et al., "A promising sensing platform toward dopamine using $\mathrm{MnO} 2$ nanowires/electro-reduced graphene oxide composites," Electrochimica Acta, vol. 296, pp. 683-692, 2019.

[17] G. Li, Y. Xia, Y. Tian et al., "Review-recent developments on graphene-based electrochemical sensors toward nitrite," Journal of The Electrochemical Society, vol. 166, no. 12, pp. B881-B895, 2019.

[18] Q. Li, Y. Xia, X. Wan et al., "Morphology-dependent MnO2/ nitrogen-doped graphene nanocomposites for simultaneous detection of trace dopamine and uric acid," Materials Science and Engineering: C, vol. 109, Article ID 110615, 2020.

[19] G. Li, J. Wu, H. Jin et al., "Titania/electro-reduced graphene oxide nanohybrid as an efficient electrochemical sensor for the determination of allura red," Nanomaterials, vol. 10, no. 2 , p. 307, 2020.

[20] D. Li, M. B. Müller, S. Gilje, R. B. Kaner, and G. G. Wallace, "Processable aqueous dispersions of graphene nanosheets," Nature Nanotechnology, vol. 3, no. 2, pp. 101-105, 2008.

[21] Y. Si and E. T. Samulski, "Exfoliated graphene separated by platinum nanoparticles," Chemistry of Materials, vol. 20, no. 21, pp. 6792-6797, 2008.

[22] X.-Z. Tang, Z. Cao, H.-B. Zhang, J. Liu, and Z.-Z. Yu, "Growth of silver nanocrystals on graphene by simultaneous reduction of graphene oxide and silver ions with a rapid and efficient one-step approach," Chemical Communications, vol. 47, no. 11, pp. 3084-3086, 2011.
[23] J. Li, J. Liu, G. Tan et al., "High-sensitivity paracetamol sensor based on Pd/graphene oxide nanocomposite as an enhanced electrochemical sensing platform," Biosensors and Bioelectronics, vol. 54, pp. 468-475, 2014.

[24] L. Zhang, L. Yang, L. Zhang, and D. W. Li, "Electrocatalytic oxidation of NADH on graphene oxide and reduced graphene oxide modified screen-printed electrode," International Journal of Electrochemical Science, vol. 6, pp. 819-829, 2011.

[25] H. Chang, X. Wu, C. Wu, Y. Chen, H. Jiang, and X. Wang, "Catalytic oxidation and determination of $\beta$-NADH using self-assembly hybrid of gold nanoparticles and graphene," The Analyst, vol. 136, no. 13, pp. 2735-2740, 2011.

[26] P. K. Simson, R. Manjunatha, C. Nethravathi, G. S. Suresh, M. Rajamathi, and T. V. Venkatesha, "Electrocatalytic oxidation of $\mathrm{NADH}$ on functionalized graphene modified graphite electrode," Electroanalysis, vol. 23, pp. 842-849, 2011.

[27] J. Leng, P. Li, L. Bai, Y. Peng, Y. Yu, and L. Lu, "Facile Synthesis of Pd nanoparticles-graphene oxide hybrid and its application to the electrochemical determination of rutin," International Journal of Electrochemical Science, vol. 10, pp. 8522-8530, 2015.

[28] M. Govindhan, M. Amiri, and A. Chen, "Au nanoparticle/ graphene nanocomposite as a platform for the sensitive detection of $\mathrm{NADH}$ in human urine," Biosensors and Bioelectronics, vol. 66, pp. 474-480, 2015.

[29] C. Liu, K. Wang, S. Luo, Y. Tang, and L. Chen, "Direct electrodeposition of graphene enabling the one-step synthesis of graphene-metal nanocomposite films," Small, vol. 7, no. 9, pp. 1203-1206, 2011.

[30] L. Chen, Y. Tang, K. Wang, C. Liu, and S. Luo, "Direct electrodeposition of reduced graphene oxide on glassy carbon electrode and its electrochemical application," Electrochemistry Communications, vol. 13, no. 2, pp. 133-137, 2011.

[31] Y. Shao, J. Wang, M. Engelhard, C. Wang, and Y. Lin, "Facile and controllable electrochemical reduction of graphene oxide and its applications," Journal of Materials Chemistry, vol. 20, no. 4, pp. 743-748, 2010.

[32] Z. Guo, Z.-y. Wang, H.-h. Wang, G.-q. Huang, and M.-m. Li, "Electrochemical sensor for isoniazid based on the glassy carbon electrode modified with reduced graphene oxide-Au nanomaterials," Materials Science and Engineering: C, vol. 57, pp. 197-204, 2015.

[33] M. Pumera, "Graphene-based nanomaterials and their electrochemistry," Chemical Society Reviews, vol. 39, no. 11, pp. 4146-4157, 2010.

[34] W. Yang, K. R. Ratinac, S. P. Ringer, P. Thordarson, J. J. Gooding, and F. Braet, "Carbon nanomaterials in biosensors: should you use nanotubes or graphene?" Angewandte Chemie International Edition, vol. 49, no. 12, pp. 2114-2138, 2010.

[35] M. N. L. D. Camargo, M. Santhiago, C. M. Maroneze, C. C. C. Silva, R. A. Timm, and L. T. Kubota, "Tuning the electrochemical reduction of graphene oxide: structural correlations towards the electrooxidation of nicotinamide adenine dinucleotide hydride," Electrochimca Acta, vol. 197, pp. 194-199, 2016.

[36] Y. Yu, N. Wu, G. Peng, T. Li, L. Jiang, and H. Huang, “A simple $\alpha$-ketoglutarate electrochemical biosensor based on reduced MoS2 nanoparticle-gold nanoparticle nanocomposite," Journal of Nanoscience and Nanotechnology, vol. 18, no. 1, pp. 576-582, 2018.

[37] A. Collins, M. P. Nandakumar, E. Csöregi, and B. Mattiasson, "Monitoring of $\alpha$-ketoglutarate in a fermentation process 
using expanded bed enzyme reactors," Biosensors and Bioelectronics, vol. 16, no. 9-12, pp. 765-771, 2001.

[38] C.-L. Sun, H.-H. Lee, J.-M. Yang, and C.-C. Wu, "The simultaneous electrochemical detection of ascorbic acid, dopamine, and uric acid using graphene/size-selected $\mathrm{Pt}$ nanocomposites," Biosensors and Bioelectronics, vol. 26, no. 8, pp. 3450-3455, 2011.

[39] L. Yang, D. Liu, J. Huang, and T. You, "Simultaneous determination of dopamine, ascorbic acid and uric acid at electrochemically reduced graphene oxide modified electrode," Sensors and Actuators B: Chemical, vol. 193, pp. 166-172, 2014.

[40] F. Pariente, F. Tobalina, G. Moreno, L. Hernández, E. Lorenzo, and H. D. Abruña, "Mechanistic studies of the electrocatalytic oxidation of $\mathrm{NADH}$ and ascorbate at glassy carbon electrodes modified with electrodeposited films derived from 3,4-dihydroxybenzaldehyde," Analytical Chemistry, vol. 69, no. 19, pp. 4065-4075, 1997. 